\title{
Eye muscle surgery for infantile nystagmus syndrome in the first two years of life
}

This article was published in the following Dove Press journal:

Clinical Ophthalmology

3 November 2009

Number of times this article has been viewed

\author{
Richard W Hertle' \\ Joost Felius ${ }^{2}$ \\ Dongsheng Yang' \\ Matthew Kaufman' \\ 'The UPMC and Children's Hospital \\ of Pittsburgh Eye Centers and The \\ Laboratory of Visual and Ocular \\ Motor Physiology Pittsburgh, PA, \\ USA; ${ }^{2}$ The Retina Foundation of \\ the Southwest, Department of \\ Ophthalmology, University of Texas \\ Southwestern Medical Center, Dallas, \\ TX, USA
}

Purpose: To report visual and elctrophysioloigcal effects of eye muscle surgery in young patients with infantile nystagmus syndrome (INS).

Methods: Prospective, interventional case cohort of 19 patients aged under 24 months who were operated on for combinations of strabismus, an anomalous head posture, and nystagmus. All patients were followed at least nine months. Outcome measures, part of an institutionally approved study, included Teller acuity, head position, strabismic deviation, and eye movement recordings, from which waveform types and a nystagmus optimal foveation fraction (NOFF). Computerized parametric and nonparametric statistical analysis of data were perfomed using standard software on both individual and group data.

Results: Age averaged 17.7 months (13.1-month follow-up). Thirteen (68\%) patients had associated optic nerve or retinal disease. $42 \%$ had amblyopia, $68 \%$ had refractive errors. Group means in binocular Teller acuity $(P<0.05)$, strabismic deviation $(P<0.05)$, head posture $(P<0.001)$, and the NOFF measures $(P<0.01)$ from eye movement recordings improved in all patients. There was a change in null zone waveforms to more favorable jerk types. There were no reoperations or surgical complications.

Conclusions: Surgery on the extraocular muscles in patients aged less than two years with INS results in improvements in multiple aspects of ocular motor and visual function.

Keywords: infantile nystagmus, anomalous head posture, eye muscle surgery

\section{Introduction}

Infantile nystagmus syndrome (INS) is an ocular motor disorder of unknown etiology, which presents at birth or early infancy and is clinically characterized by involuntary oscillations of the eyes. Estimations of incidence vary from one in 350 to one in $20,000{ }^{1}$ Other clinical characteristics include: increased intensity with fixation and decreased with sleep or inattention; variable intensity in some position of gaze (a null position); changing direction in different positions of gaze (about a neutral position); decreased intensity (damping) with convergence; anomalous head posture; strabismus; and the increased incidence of significant refractive errors. ${ }^{2-5}$ INS can occur in association with congenital or acquired defects in the visual sensory system (eg, albinism, achromatopsia, and congenital cataracts).

Numerous studies of INS in infants and children confirm an age-dependent evolution of waveforms during infancy from pendular to jerk..$^{2,4,6,7}$ These studies reemphasize that continued clinical classification of INS as either "sensory" or "motor" is confusing and often inaccurate.
Correspondence: Richard W Hertle Children's Hospital of Pittsburgh, Ophthalmology, 45th and Penn Ave, Faculty Pavilion 8th Floor, Pittsburgh, PA I520I, USA

Email richard.hertle@chp.edu 
In an infant is diagnosed with INS, ocular motility analysis can also be helpful in determining visual status. Pure pendular or jerk waveforms without foveation periods are associated with poorer vision while waveforms of either type with extended periods of foveation are indicators of good vision.

Since formal descriptions of eye muscle surgery for head posturing associated with INS there has accumulated considerable evidence that procedures on the horizontal recti improve; anomalous head positions, electrophysiological characteristics of the nystagmus and vision and visual function. ${ }^{8-13}$ Head posturing to improve vision or visual function in patients with INS occurs in $20 \%$ to $70 \%$ of the INS population and is usually due to a static or dynamic eccentric gaze null. ${ }^{14-17}$ Its clinical expression is frequently modified by age, attention, head and neck mobility, visual acuity, monocular fixation with a latent component, ammetropia, viewing distance, systemic medications and associated strabismus. . $^{14,17,18}$

This report characterizes the clinical and electrophysiological consequences of eye muscle surgery on patients under 24 months, ie, "early surgery" for INS with an associated anomalous head posture and/or strabismus.

\section{Methods}

All testing, data collection, analysis, and reporting were approved by the Institutional Review Boards of the Children's Hospital of Pittsburgh of UPMC and the University of Pittsburgh. All procedures observed the Declaration of Helsinki and informed consent/assent was obtained from all patients/ families. Inclusion criteria for patients were clinically diagnosed and electrophysiologically confirmed INS, strabismus, and/or an eccentric gaze null position were confirmed with eye movement recordings. There was no prior surgery on the extraocular muscles before that performed by the author (RWH). None of these patients were on medications known to affect the ocular motor system. All families and patients reported compliance with, and were observed to be compliant with, amblyopia therapy and spectacle wear prior to surgery. Those specific outcome measures prospectively analyzed for this study included: pre- and postoperative; head posture, binocular best optically corrected null zone Teller acuity, primary position ocular deviation, INS waveform changes, and the nystagmus optimal foveation fraction (NOFF).

\section{Teller acuity card procedure}

Teller acuity card (TAC) testing was conducted according to published methods at age-appropriate viewing distances, and results were compared to published normative data. The child is presented with a gray card containing a grating on one side that is matched in mean luminance to the gray background. In the standard protocol, the location of a vertical grating is randomly switched to the left or right of central gaze. ${ }^{19,20}$ Due to the patients' nystagmus, visual acuity was tested with the TACs held vertically so that the gratings were horizontally oriented. Binocular acuity was tested and used as the outcome measure for this study. All of the acuities were measured by one tester (RWH). Patients all had visual acuity tested in their preferred head position. Patients were tested with their full optical correction if they had myopia worse than 1.00 diopters (D), hyperopia greater than $3.00 \mathrm{D}$ in spherical equivalent, or astigmatism (in plus cylinder notation) of $1.5 \mathrm{D}$ or more. ${ }^{19,20}$ Two measurements of visual acuity were performed within hours of each other both preoperatively and at 6-8 weeks postoperatively.

\section{Ocular motor and standard clinical evaluations}

Ocular motor examination also included a determination of heterophoria/tropia at distance $(3-6 \mathrm{~m})$ and near $(33 \mathrm{~cm})$ in all diagnostic positions of gaze. Cycloplegic refraction, tonometry, and examination of the anterior and posterior segments and fundus photographs, electroretinography and motion visual-evoked potential (mVEP) testing were performed when retinal and/or optic nerve pathology were clinically suspected. Evaluation of the ocular motor oscillations included measurement of any anomalous head posture and changes in the oscillation in primary position, at near, and in diagnostic positions of gaze under monocular and binocular conditions. An eccentric null position for which surgery was indicated was determined clinically and by eye movement recordings.

\section{Eye movement recordings}

All 19 patients had eye movement recordings. The presentation of stimuli, and the acquisition, display and storage of data were controlled by a series of personal computers using standard Microsoft ${ }^{\circledR}$ and Matlab ${ }^{\circledR}$ software and specially designed and created software such as Eyelink Co., Applied Science Laboratories, Visual and EXperimentation (VEX), and Real-time EXperimentation (REX) packages.

The horizontal and vertical eye movement recordings were made using an Eyelink ${ }^{\circledR}$ IR reflection method or remote video eye movement system with a bandwidth from $0-1000 \mathrm{~Hz}$. The signals were calibrated (using the end of the fast phase during the nystagmus cycle) at the 
beginning of the recording session using $3^{\circ}$ pictures or stationary $1^{\circ}$ targets presented on a screen at a distance of 1.5 meters from the patient. Data were sampled at $500 \mathrm{~Hz}$ to $1000 \mathrm{~Hz}$. Calibration was accomplished monocularly both on line and later by Matlab computer program. Fixation was clinically coerced between $0^{\circ}$ and $30^{\circ}$ horizontal and vertically with both eyes then fixation at $0^{\circ}$ with both eyes was accomplished as long as possible up to 10 minutes (to rule out aperiodic alternating nystagmus). ${ }^{4}$ The types of waveforms present were classified according the previously described waveforms associated with INS. ${ }^{2,15}$

\section{Head posture measurements}

Measurement of the patient's head position was recorded and data obtained twice preoperatively and postoperatively using a previously described head posture measurement system.

\section{Nystagmus optimal foveation fraction}

Similar to the expanded nystagmus acuity function (NAFX), the algorithm was designed around simultaneous criteria for velocity and excursions from a reference position however with added freedom in positional zero, thus allowing for head and body movement during testing. For the data record of each patient, consisting of horizontal position $x(t)$ and velocity $v(t)$, a time window of finite length (four seconds) was stepped through the data in search for the four-second segment with the optimal number of data points satisfying both criteria. (The four-second window length was chosen so that it would contain approximately five to 10 oscillations; A shorter time window would presumably not contain enough data, while a longer window would increase the susceptibility to head and body movements. Preliminary analyses on a subset of patients using window lengths of 2-10 seconds indicated that this choice is not crucial for the result.) During each step $i$, data points in the window were identified that met both criteria: $\left|x(t) x_{r e f, i}\right| \leq x_{\max }$ and $|v(t)| \leq v_{\max }$. In the former constraint, the reference position $x_{r e f, i}$ was adjusted with each step according to the median position across the four-second window. (An initial value of $x_{r e f}$ was chosen manually by the examiner by selecting a probable foveation event during any oscillation based on visual inspection of the position and velocity traces. This constituted a relatively small correction for waveforms where foveation generally takes place at one extreme of the oscillation, eg, in jerk-nystagmus. In the case of pendular waveforms, a point at either extreme of the oscillation might be selected). This provided an initial identification of foveation periods, which were subsequently 'cleaned up' by discarding very brief $(<7 \mathrm{~ms}$ ) foveation periods and by bridging small gaps $(<35 \mathrm{~ms})$ between adjacent foveation periods in strict analogy with the NAFX algorithm.

In order to find the optimal segment, ideally, the foursecond window would step through the data record one data point (here, $2 \mathrm{~ms}$ ) at a time. To reduce computation time we let the four-second window move in 0.5 -second steps. The particular four-second data segment for which the number of data points that met both criteria was maximal presumably corresponded to the four seconds of data within the data record with optimal foveation potential. Thus, the fraction $p_{\text {opt }}$ of points in the optimal segment that meet both criteria is found. Because this fraction is bound to a finite interval (0 to 1$)$, it is unappealing as an outcome measure from a statistics standpoint. Furthermore, for values of $p_{\text {opt }}$ that are close to zero, a small change may represent a relatively larger effect than for intermediate values of $p_{\text {opt }}$. For these two reasons, a logistic transformation was applied to convert $p_{\text {opt }}$ to a scale that is statistically better tractable: $\mathrm{NOFF}=\mathrm{In}$ $\left(P_{\text {opt }} /\left(P_{\text {opt }}\right)\right)$ and that 'stretches' the extremes. This transformation is similar to the one typically used in logistic regression models; it expresses the NOFF in logit units.

To explore suitable values for $x_{\max }$ and $v_{\max }$, all calculations were repeated for the following $\left(x_{\max }, v_{\max }\right)$ combinations: $\left(0.5^{\circ}, 4^{\circ} / \mathrm{s}\right),\left(1^{\circ}, 4^{\circ} / \mathrm{s}\right),\left(1^{\circ}, 6^{\circ} / \mathrm{s}\right),\left(1^{\circ}, 8^{\circ} / \mathrm{s}\right)$ and $\left(2^{\circ}, 8^{\circ} / \mathrm{s}\right)$. For each combination, floor $\left(P_{o p t}<0.01\right)$ and ceiling $\left(P_{o p t}>0.8\right)$ effects were evaluated as well as the relation between NOFF and visual acuity. Note that these $\left(x_{\max }, v_{\max }\right)$ combinations are all within the range of position-velocity criteria used in the NAFX algorithm. ${ }^{21}$

The NOFF analysis of the masked data took place at the Retina Foundation of the Southwest by an author (JF). Postoperative eye movement recordings were obtained 4-6 weeks after surgery. In all analyses, the NOFF value corresponding to the patient's preferred eye was used, ie, the eye that was not strabismic and/or the eye with the better visual acuity. For patients with no a priori indication of a preferred or better-seeing eye, the eye was used that yielded the highest NOFF value (Figure 2).

\section{Statistical analysis}

The resulting NOFF values did not strongly depend on the choice of $\left(x_{\max }, v_{\max }\right)$ parameter combination. For relatively 'wide' criteria (eg, $\left[2^{\circ}, 8 \% \mathrm{~s}\right]$ ), larger NOFF values were found and NOFF $>0.80$ in $11 \%$ of the data records (ceiling effect). For relatively 'narrow' criteria (eg, $\left.\left[0.5^{\circ}, 4^{\circ} / \mathrm{s}\right]\right)$, smaller NOFF values were found and NOFF $<0.05$ in $6 \%$ of the data records (floor effect). For each of the intermediate 


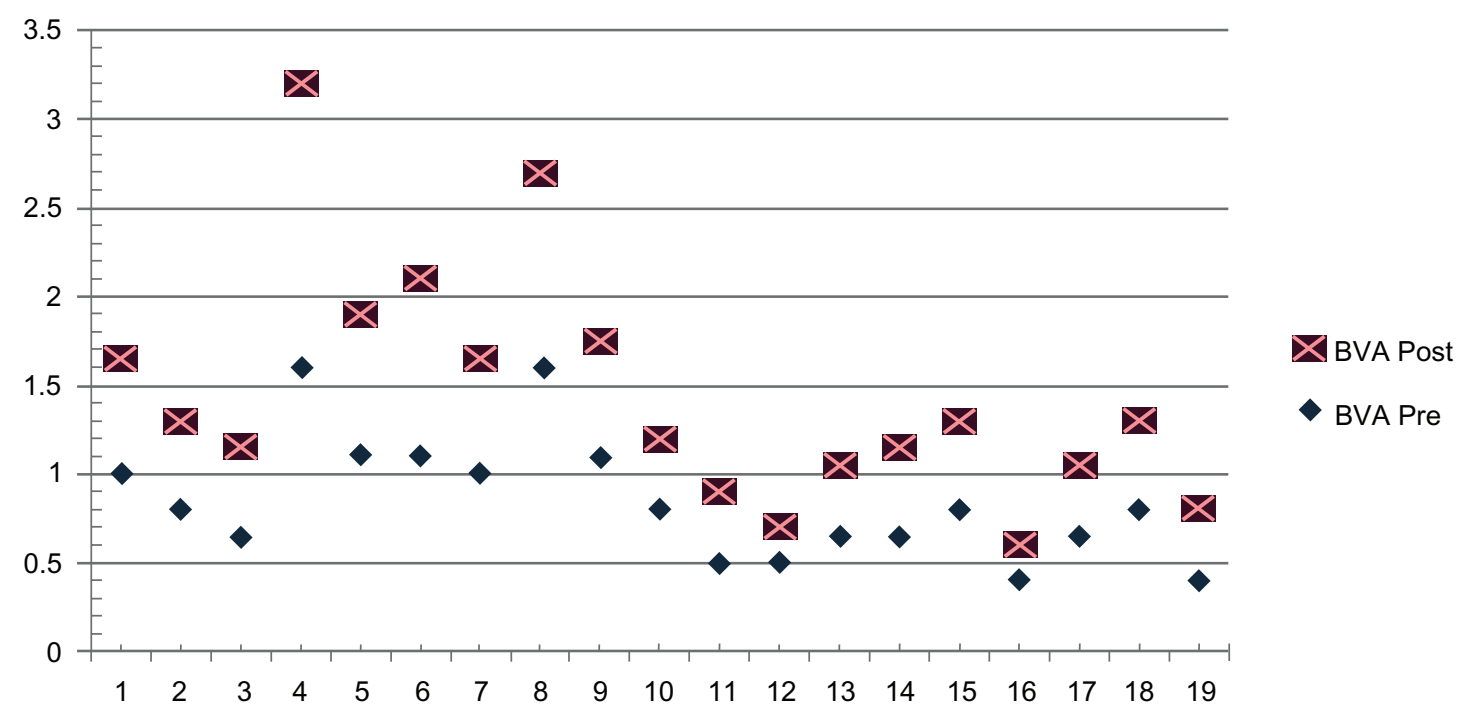

Figure I LogMAR acuity plot data pre- and postoperative.

Notes: Preoperative-postoperative unity plot of binocular acuity for the 19 patients showing a significant group improvement. LogMAR scale: the $Y$ axis is LogMAR acuity and the $\mathrm{X}$ axis is patient number.

Abbreviations: BVA, binocular teller acuity card LogMAR acuity; LogMAR, Log of the minimal angle of resolution.

parameter combinations $\left(\left[1^{\circ}, 4^{\circ} / \mathrm{s}\right],\left[1^{\circ}, 6^{\circ} / \mathrm{s}\right],\left[1^{\circ}, 8^{\circ} / \mathrm{s}\right]\right)$ both ceiling effect and floor effect occurred in $<5 \%$ of the data records. Group mean analysis of pre- and postoperative head posture was accomplished using a Fisher's exact test (Figures 1 and 2). A Wilcoxon signed-rank test was performed to evaluate whether or not there was a significant visual acuity change between the pre- and postsurgery LogMAR. Reported $\mathrm{p}$ values are two-tailed. Analyses were conducted using GB-STAT (version 10; Dynamic Microsystems, Inc., Silver Spring, MD).

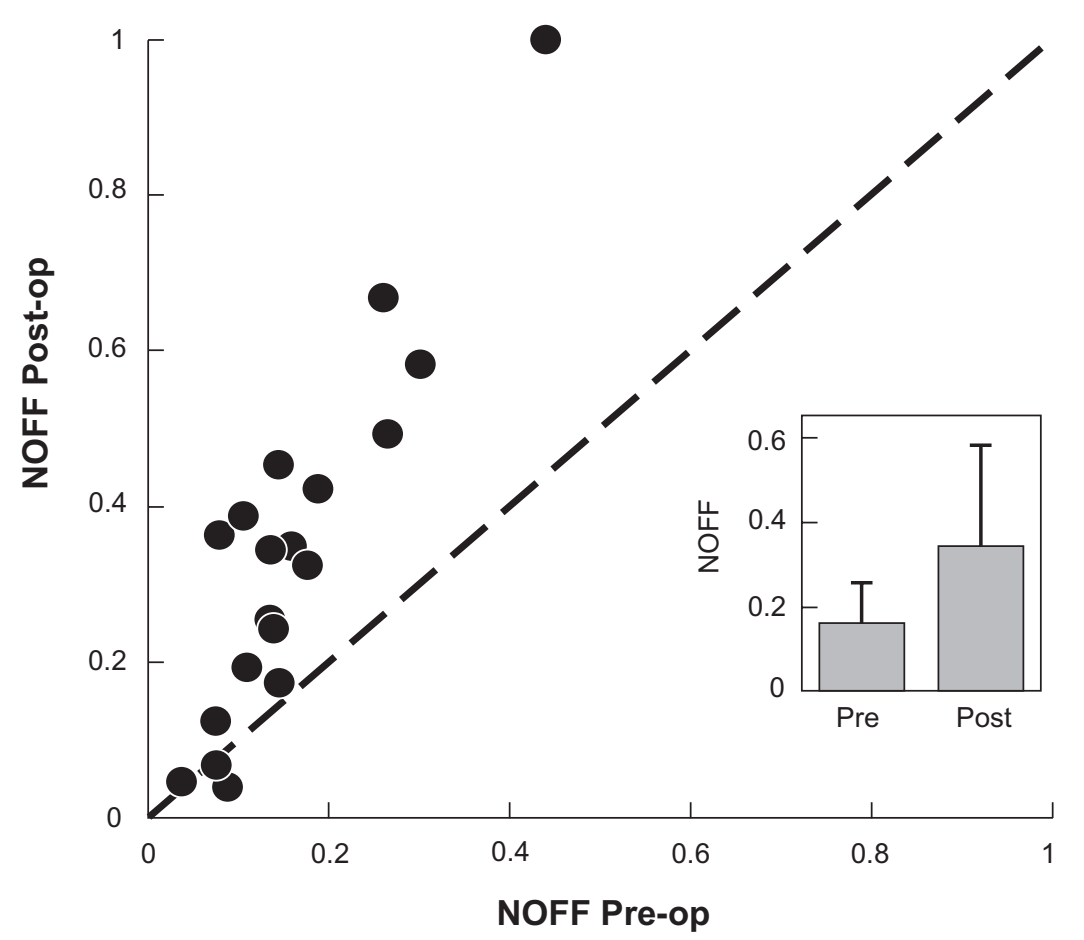

Figure 2 Unity plot nystagmus optimal foveation fraction pre- and postoperative.

Notes: Preoperative-postoperative unity plot of NOFF for the 19 patients showing a significant improvement. $0=$ no foveation; I = complete foveation for selected eye movement segment (see text for NOFF details); circle = patients.

Abbreviation: NOFF, nystagmus optimal foveation fraction. 


\section{Results}

\section{Patient characteristics}

Of 725 eye movement recordings performed between the years 2004-2008 in 430 patients with INS, 19 patients (4.1\%) are the subjects of this study and ranged in age from 5-29 months (average age 17.7 months), 12 were male, follow up ranged from 9-22 months (average age 17.1 months), and 18 of the 19 patients had other eye disease (Tables 1 and 2).

\section{Surgery}

The goal of surgery was to treat the patient's strabismus, anomalous head posture and nystagmus. No patients with fusion prior to surgery lost fusion after surgery. In those patients whose plan included treating an anomalous head posture there was a bilateral symmetric minimal limitation of gaze in the opposite direction of the original head posture without an induced vertical, horizontal or torsional gaze incomitance (Table 1).

\section{Anomalous head posture}

In those 11 patients who had an anomalous head posture the postoperative change in head posture improved significantly (within $\pm 5^{\circ}$ ) (Table 2).

\section{Teller acuity cards}

Acuity outcome data reported in this study included repeat preoperative (within one week) and postoperative (at 6-8 weeks after surgery) best binocular acuity in the patient's null zone. We used two-month postsurgical acuity data to allow for complete healing postoperatively, and avoid age-related increase in acuity in the younger age group due to visual system maturation. Teller acuity is reported as the Log of the minimal angle of resolution (LogMAR) (Figure 2). The average null zone acuity as group was $0.6(20 / 80)$ preoperatively and significantly different at $0.4(20 / 50)$ postoperatively $(P=0.003)$. Two patients did not change while 17 , had a 0.1 or greater, $17(71 \%)$, had a 0.2 or greater and five $(21 \%)$, measured a 0.3 or greater LogMAR improvement in acuity (Figure 1).

Table I Patient demographics

\begin{tabular}{|c|c|c|c|c|}
\hline Patient \# & $\begin{array}{l}\text { Age surgery } \\
\text { (Months) }\end{array}$ & $\begin{array}{l}\text { Follow-up } \\
\text { (Months) }\end{array}$ & Eye diagnoses & Systemic diagnoses \\
\hline I & 22 & 15 & OND/OCA/NLDO/AHP & None \\
\hline 2 & 29 & 10 & OCA/AHP/ET & None \\
\hline 3 & 16 & 9 & AHP & None \\
\hline 4 & 9 & 15 & $\mathrm{OND} / \mathrm{CVI} / \mathrm{XT}$ & $\begin{array}{l}\text { Microcephaly, DD, CP, dysgammaglob- } \\
\text { ulinemia, GERD, seizure disorder }\end{array}$ \\
\hline 5 & 17 & 9 & Cone-Rod Dystrophy/XT/AHP & Prematurity \\
\hline 6 & 9 & 17 & OND/ET/Amblyopia & $\begin{array}{l}\text { Posthemorrhagic hydrocephalus, } \\
\text { hypothyroid }\end{array}$ \\
\hline 7 & 22 & 11 & OCA/ET/AHP & None \\
\hline 8 & 18 & 11 & CVI/XT/ONH//ET/OND/Amblyopia & $\begin{array}{l}\text { Chromosome } 2 \text { anomaly, CHD, hearing } \\
\text { loss }\end{array}$ \\
\hline 9 & 14 & 17 & AHP/OCA & None \\
\hline 10 & 21 & 8 & IPAN/ET/AHP & Hepatitis C, prematurity, plagiocephaly \\
\hline II & 20 & 13 & AHP/IPAN/XT/Amblyopia/OND & None \\
\hline 12 & 21 & 8 & AHP/ONH/FH/OCA/V-ET/OAIO & Cardiac arrhythmia, otitis media \\
\hline 13 & 22 & 12 & OCA/AHP & None \\
\hline 14 & 5 & 21 & OCA/ET/OND/FH & None \\
\hline 15 & 23 & 22 & AHP/ET & None \\
\hline 16 & 17 & 10 & AHP/OND/CVI/XT/IPAN/Amblyopia & None \\
\hline 17 & 18 & 13 & OND/AHP/Amblyopia/XT/DVM & None \\
\hline 18 & 12 & 15 & $\mathrm{ONH} / \mathrm{CVI} / \mathrm{AHP} / \mathrm{V}-\mathrm{XT}$ & Gastroschisis \\
\hline 19 & 22 & 11 & ET & None \\
\hline
\end{tabular}

Abbreviations: OND, optic nerve dysplasia; OCA, oculocuteaneous albinism; NLDO, nasolacrimal duct obnstruction; AHP, anomalous head posture; ET, esotropia; DD, developmental delay; CP, cerebral palsy; GERD, gastroesophogeal reflux disease; CVI, cortical vision impairment; XT, exotropia; IPAN, infantile periodic alternating nystagmus; $\mathrm{ONH}$, optic nerve hypoplasia; V-ET, "V" pattern esotropia; FH, foveal hypoplasia; DVM, delayed visual maturation; V-XT, "V" pattern exotropia. 
Table 2 Patient data results

\begin{tabular}{|c|c|c|c|c|c|c|c|c|}
\hline Patient & Surgery & AHP Pre- & AHP Post- & Strab Pre- & Strab Post- & Refractive error & Wave Pre- & Wave Post- \\
\hline I & REC/RES OU & R Face & 0 & 0 & 0 & $+0.50+1.00 \times 90 \mathrm{OU}$ & $A P$ & $J$ \\
\hline 2 & REC/RES OU & R Face & 0 & I2 ET & $4 \mathrm{ET}$ & $+2.25 \mathrm{OU}$ & $J$ & JEF \\
\hline 3 & $\begin{array}{l}\text { BSOT/BIRR/ } \\
\text { BMRT }\end{array}$ & Chin up & 0 & 0 & 0 & $+2.00+2.5 \times 90 \mathrm{OU}$ & J & JEF \\
\hline 4 & $\begin{array}{l}\text { BSOT/BIRR/ } \\
\text { BMREC }\end{array}$ & Chin up & 0 & I5 ET & $4 \times \mathrm{T}$ & $+3.5 \mathrm{OU}$ & J & JEF, BDJ \\
\hline 5 & $\begin{array}{l}\text { BSOT/BIRR/ } \\
\text { BMRT }\end{array}$ & Chin u & 0 & $12 \mathrm{ET}$ & $4 \mathrm{ET}$ & $+7.5 \mathrm{OU}$ & AP & JEF \\
\hline 6 & $\begin{array}{l}\text { BMRREC/ } \\
\text { BLRES }\end{array}$ & None & None & $50 \mathrm{ET}$ & $5 \times T$ & $\begin{array}{l}-1.0+2.25 \times 120 \mathrm{OD} \\
-3.25+3.5 \times 90 \mathrm{OS}\end{array}$ & AP & JEF \\
\hline 7 & BMRT/BLRT & None & None & 0 & 0 & $+2.25+1.0 \times 90 \mathrm{OU}$ & $J$ & JEF \\
\hline 8 & BMREC/BLRT & None & None & $30 \mathrm{ET}$ & $6 \times \mathrm{T}$ & -4.5 OU & AP & JEF \\
\hline 9 & $\begin{array}{l}\text { REC/RES OU } \\
\text { TRANS }\end{array}$ & $\mathrm{R}$ face/tilt & 0 & $20 \mathrm{ET}$ & $4 \mathrm{ET}$ & $\begin{array}{l}+4.0+.75 \times 70 \\
O D \times 100 \text { OS }\end{array}$ & $\mathrm{P}$ & JEF \\
\hline 10 & BMRT/BLRT & IPAN & PAN & $30 \mathrm{ET}$ & 0 & $+4.5+1.5 \times 90 \mathrm{OU}$ & AP & BDJ \\
\hline II & $\begin{array}{l}\text { BSREC/BIO/ } \\
\text { BMREC }\end{array}$ & Chin down & 0 & $20 \times T$ & $4 \times \mathrm{T}$ & $\begin{array}{l}-1.75+1.5 \times 70 \\
O D \times 110 O S\end{array}$ & J & JEF \\
\hline 12 & $\begin{array}{l}\text { BMREC/ } \\
\text { BSREC/BIO }\end{array}$ & Chin down & 0 & V-ET20 & 3 ET & $+1.0+2.5 \times 90 \mathrm{OU}$ & AP & BDJ \\
\hline 13 & BMRT/BLRT & None & None & 0 & 0 & $+2.0 \mathrm{OU}$ & $A P$ & JEF \\
\hline 14 & BMRT/BLREC & None & None & $24 \times T$ & 0 & $-0.5+1.0 \times 90 \mathrm{OU}$ & $J$ & JEF \\
\hline 15 & $\mathrm{BMRT} / \mathrm{BLRT}$ & None & None & 0 & 0 & $\begin{array}{l}+1.0 \text { OD }+1.00+1.00 \times \\
90 \text { OS }\end{array}$ & J & BDJ \\
\hline 16 & $\begin{array}{l}\text { BSREC/BIO/ } \\
\text { BMRT }\end{array}$ & Chin down & 0 & 0 & 0 & $+2.0 \mathrm{OU}$ & $J$ & JEF \\
\hline 17 & BLREC/BMRT & None & None & $30 \times \mathrm{T}$ & $4 \mathrm{ET}$ & $+7.0 \mathrm{OU}$ & $A P$ & $J$ \\
\hline 18 & $\begin{array}{l}\text { BLREC/BIRR/ } \\
\text { BSOT }\end{array}$ & Chin up & 0 & $45 \times \mathrm{T}$ & $6 \times \mathrm{T}$ & $+7.5+1.5 \times 90 \mathrm{OU}$ & AP & J \\
\hline 19 & BMREC/BLRT & None & None & $30 \mathrm{ET}$ & $4 \mathrm{ET}$ & $+1.75 \mathrm{OU}$ & AP & JEF \\
\hline
\end{tabular}

Abbreviations: AHP, anomalous head posture; pre-, preoperative; post-, postoperative; strab, strabismus in primary position; wave, waveform on eye movement recordings; REC, recession; RES, resection; OU, both eyes; BSOT, bilateral superior oblique tenectomy; BIRR, bilateral inferior rectus recession; BMRT, bilateral medial rectus tenotomy with reattachment; BMREC, bilateral medial rectus recession; BLRES, bilateral lateral rectus resection; BLRT, bilateral lateral rectus tenotomy with reattachment; TRANS, transposition; BSREC, bilateral superior rectus recession; BIO, bilateral inferior oblique myectomy; BLREC, bilateral lateral rectus recession; R, right; IPAP, infantile periodic alternating nystagmus; 0 , head posture within $8^{\circ}$ straight; ET, esotropia; XT, exotropia; $\mathrm{V}$, "V" pattern; AP, asymmetric pendular; J, jerk; JEF, jerk with extended foveation; BDJ, bidirectional jerk.

\section{Nystagmus optimal foveation fraction}

A unity plot of NOFF values were compared and shown in Figure 2. The mean improvement in NOFF values from 0.16 before surgery to 0.34 after surgery was significant (signed rank test, $Z=3.7 ; P=0.0002$ ). It can be seen that all but two patients showed improvements in their NOFF and that larger improvements were seen for patients with larger preoperative NOFF values (Figures 3, 4).

\section{Discussion}

We have used the National Eye Institute workshop on classification of eye movement abnormalities and strabismus
(CEMAS) in this group of patients. ${ }^{3}$ Visual acuity in these patients is affected by unpredictable combinations of ocular motor (eccentric null zones, damping with convergence, monocular intensity changes, periodicity, strabismus and attention) and sensory system defects (ammetropia, amblyopia, and foveal or optic nerve dysplasia). There is quantitative data that if the slow foveation periods occurring during each beat of nystagmus can be lengthened or increased by the patient or by therapeutic interventions (ie, medicines, surgery, contact lenses, acupuncture, biofeedback) some of a patient's visual function may be increased., ${ }^{2,11,22,24}$ In Anderson's second edition textbook printed in 1959, Ocular Vertical Deviations 

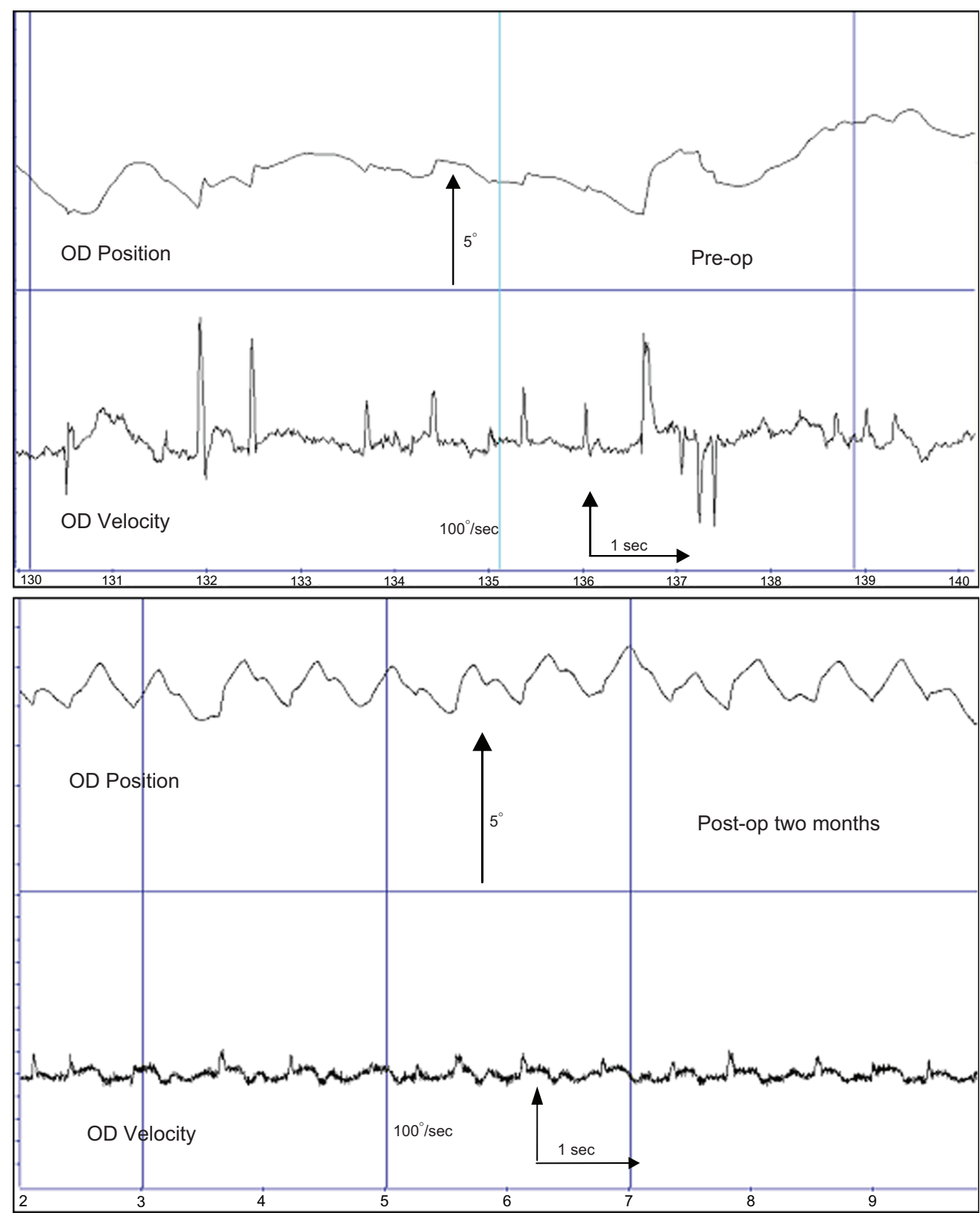

Figure 3 Eye movement recording of patient 2.

Notes: Eye movement recording data from patient \#2 within one week preoperatively and two months after surgery. The 10-second traces shows a change from irregular pendular, occasional jerk waveforms with floating (unstable) fixation preoperatively to a waveform showing more stable fixation and jerk and foveating saccades, early bidirectional jerk waveforms, one of the most favorable outcomes for visual function in INS patients. Abbreviation: INS, infantile nystagmus syndrome.

and the Treatment of Nystagmus, he states: "It has been found that such operation not only may greatly lessen torticollis, but may also improve vision by lessening the nystagmus itself." ${ }^{24}$ We hypothesized that the improvement in INS resulted in improved vision and visual function and was directly related to the surgical procedure.

Sensitive periods during development of visual function are well recognized, eg, visual acuity, stereopsis, contrast, color, and binocularity. ${ }^{25}$ Early eye muscle surgery for eye movement disorders in not a new idea. The results obtained by Birch and colleagues suggest that early surgical alignment in those patients with infantile esotropia is associated with better stereopsis and higher prevalence of fusion without adverse motor outcomes, because early surgery minimizes the duration of misalignment, not because alignment is achieved during an early critical period of visual maturation. ${ }^{25}$ In a comparison clinical trial that following surgery, Drover found a comparison group of patients showed rapid development 


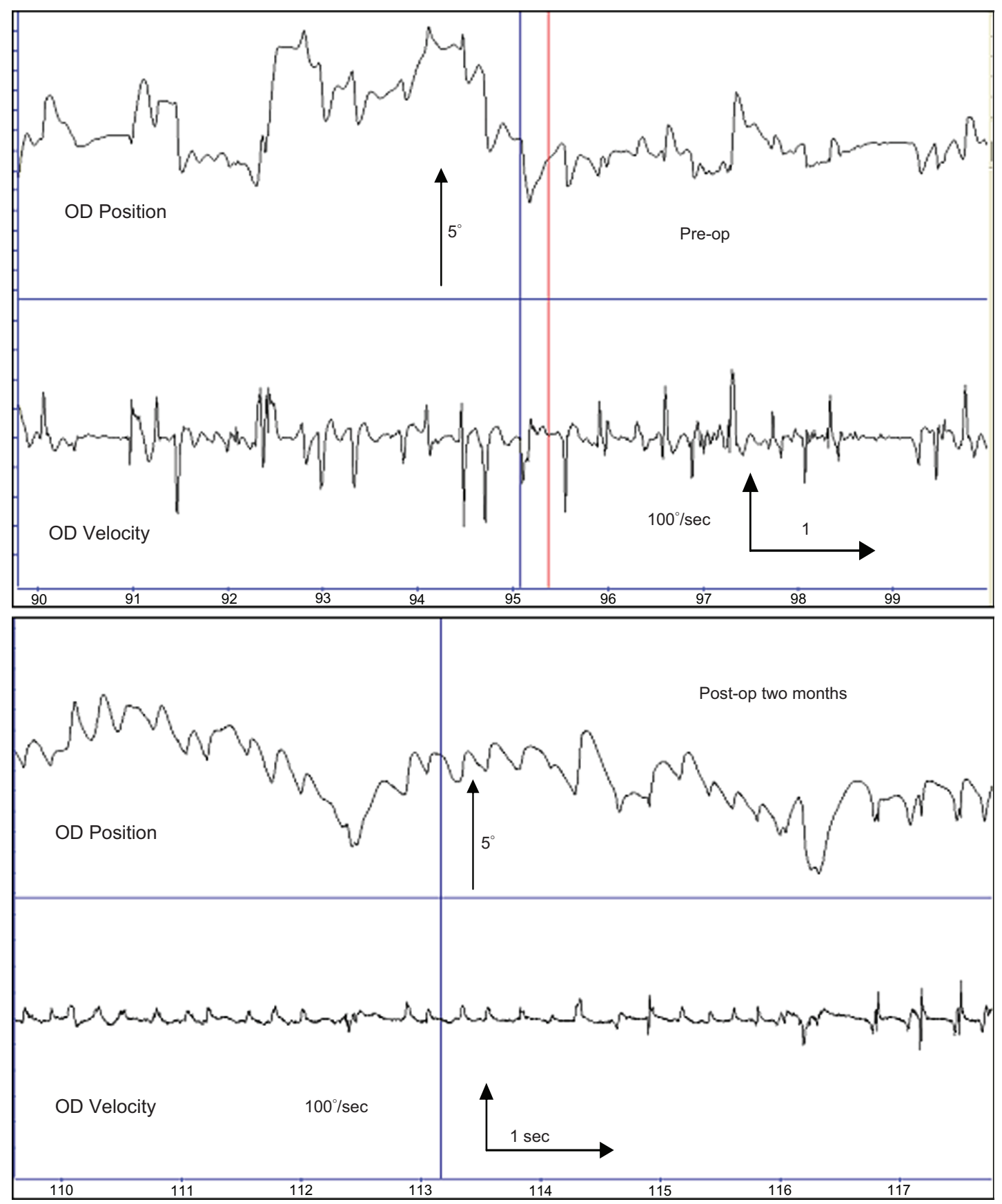

Figure 4 Eye movement recording of patient 16.

Notes: Eye movement recording data from patient \#16 within one week preoperatively and two months after surgery. The 10 -second traces shows a change from irregular asymmetric pendular, occasional jerk waveforms with floating (unstable) fixation preoperatively to a waveform showing more stable fixation and jerk with extended foveation, a more favorable outcome for visual function in INS patients.

Abbreviation: INS, infantile nystagmus syndrome.

and possessed motor skills comparable to those of normal children, suggesting that early surgery is beneficial to both visual and motor development. ${ }^{26}$ Early surgery for infantile esotropia promotes the development of cortical visual motion processing, whereas standard surgery is associated with abnormal mVEPs. ${ }^{27}$ In the final report of the early versus late infantile strabismus surgery study, a controlled, prospective, multicenter study children operated early had better gross stereopsis at age six as compared to children operated late. ${ }^{28}$ Clinicians now consider offering early surgery to patients with large-angle, constant infantile esotropia at or before the age of 10 months. ${ }^{29}$ 
We suggest that patients who use a consistent eccentric null zone to improve their vision and visual function benefit from having their nystagmus improved and null zone broadened, deepened and moved within $5^{\circ}$ of primary position, regardless of how much of the time they adopt a head posture. Many patients do not posture most of the time because they cannot posture most of the time, and, if they could, they would. The neck and facial muscles prohibit constant use of an eccentric head posture. ${ }^{30}$ The use of "time spent posturing" may not be a valid clinical indicator of the need for treatment.

In summary, we have found that "early" eye muscle surgery in patients with INS resulted in significant, measurable, improvements in head posture, foveation function, waveforms and binocular best corrected Teller acuity. The data collected on these patients support the hypothesis that surgical manipulation of the extraocular muscles inpatients with oculographically INS "improves" the oscillation and visual functions. There are measured increases in foveation periods and the NOFF. The subjective consequences of changing the nystagmus cannot be measured solely by high spatial frequency vision. Although patients will have absolute improvement in visual acuity, this is in the range of 1 to 3 Snellen lines. In many patients with low vision, this can make the difference between driving and not driving. Although physiology of the nystagmus reduction is not completely understood, recently discovered and possibly proprioceptive nerve endings in the extraocular muscles at the tendino-scleral interface (its "enthesis")may shed light on a further mechanism of action of eye muscle surgery in reducing nystagmus. It may be likely that afferent information from the extraocular muscles (either as proprioceptive signals or as other sensory information) serves as a continuous calibration. The clinical and electrophysiological consequences of extraocular muscle surgery in patients with INS may be attributable to interruption of the afferent proprioceptive loop, producing a damped peripheral ocular motor response to the nystagmus signal.

This report provides further evidence that surgery on the extraocular muscles improves, but does not eliminate, head position and nystagmus resulting in gains in visual function in patient with INS.

\section{Disclosures}

The authors report no conflicts of interest in this work.

\section{References}

1. Norn MS. Congenital idiopathic nystagmus. Incidence and occupational prognosis. Acta Ophthalmol (Copenh). 1964;42(4):889-896.

2. Abadi RV, Bjerre A. Motor and sensory characteristics of infantile nystagmus. Br J Ophthalmol. 2002;86(10):1152-1160.
3. CEMAS Working Group; Richard W. Hertle MD, editors. A National Eye Institute-sponsored workshop and publication on the Classification of Eye Movement Abnormalities and Strabismus (CEMAS). Bethesda, MD: The National Eye Institute Publications, The National Institutes of Health; 2001.

4. Hertle RW, Dell'Osso LF. Clinical and ocular motor analysis of congenital nystagmus in infancy. J AAPOS. 1999;3(2):70-79.

5. Hertle RW, Maldanado VK, Maybodi M, Yang D. Clinical and ocular motor analysis of the infantile nystagmus syndrome in the first 6 months of life. Br J Ophthalmol. 2002;86(6):670-675.

6. Dell'osso LF, Daroff RB. Congenital nystagmus waveforms and foveation strategy. Doc Ophthalmol. 1975;39(1):155-182.

7. Reinecke RD. Costenbader Lecture. Idiopathic infantile nystagmus: diagnosis and treatment. JAAPOS. 1997;1(2):67-82.

8. Dell'Osso LF, Hertle RW, Williams RW, Jacobs JB. A new surgery for congenital nystagmus: effects of tenotomy on an achiasmatic canine and the role of extraocular proprioception. J AAPOS. 1999;3(3): 166-182.

9. Hertle RW, Anninger W, Yang D, et al. Effects of extraocular muscle surgery on 15 patients with oculo-cutaneous albinism (OCA) and infantile nystagmus syndrome (INS). Am J Ophthalmol. 2004;138(6): 978-987.

10. Hertle RW, Dell'Osso LF, FitzGibbon EJ, et al. Horizontal rectus tenotomy in patients with congenital nystagmus: results in 10 adults. Ophthalmology. 2003;110(11):2097-2105.

11. Kestenbaum A. Nystagmus; review of the literature in 1946-1954. Bibl Ophthalmol. 1957;13(49):221-286.

12. Nelson LB, Wagner RS, Harley RD. Congenital nystagmus surgery. Int Ophthalmol Clin. 1985;25(4):133-138.

13. Wang ZI, Dell'Osso LF, Tomsak RL, Jacobs JB. Combining recessions (nystagmus and strabismus) with tenotomy improved visual function and decreased oscillopsia and diplopia in acquired downbeat nystagmus and in horizontal infantile nystagmus syndrome. JAAPOS. 2007;11(2):135-141.

14. Abadi RV, Pascal E. Periodic alternating nystagmus in humans with albinism. Invest Ophthalmol Vis Sci. 1994;35(12):4080-4086.

15. Dell'Osso LF, van der Steen J, Steinman RM, Collewijn H. Foveation dynamics in congenital nystagmus. I: Fixation. Doc Ophthalmol. 1992;79(1):1-23.

16. Gonzalez C, Seth RK, Ramos-Esteban JC. Change in head posture and character of nystagmus in a patient with neurological upbeat nystagmus. Binocul Vis Strabismus Q. 2007;22(3):179-184.

17. Shallo-Hoffmann J, Faldon M, Tusa RJ. The incidence and waveform characteristics of periodic alternating nystagmus in congenital nystagmus. Invest Ophthalmol Vis Sci. 1999;40(11):2546-2553.

18. Dell'Osso LF, van der Steen J, Steinman RM, Collewijn H. Foveation dynamics in congenital nystagmus. III: Vestibulo-ocular reflex. Doc Ophthalmol. 1992;79(1):51-70.

19. Dobson V, Quinn GE, Siatkowski RM, et al; Agreement between grating acuity at age 1 year and Snellen acuity at age 5.5 years in the preterm child. Cryotherapy for Retinopathy of Prematurity Cooperative Group. Invest Ophthalmol Vis Sci. 1999;40(2):496-503.

20. Weiss AH, Kelly JP. Acuity development in infantile nystagmus. Invest Ophthalmol Vis Sci. 2007;48(9):4093-4099.

21. Dell'Osso LF, Jacobs JB. An expanded nystagmus acuity fuction: intraand intersubject prediction of best-corrected visual acuity. Doc Ophthalmol. 2002;104(3):249-276.

22. Abel LA, Wang ZI, Dell'Osso LF. Wavelet analysis in infantile nystagmus syndrome: limitations and abilities. Invest Ophthalmol Vis Sci. 2008;49(8):3413-3423.

23. Dorn L, Curkovic T, Dorn V. Foveation period and waveforms of congenital ocular nystagmus. Coll Antropol. 2005;29(Suppl 1):99-101.

24. Anderson J. Ocular Vertical Deviations and the Treatment of Nystagmus, 2nd ed. Philadelphia, PA: JB Lippincott Company; 1959. p. 170.

25. Birch EE, Cheng C, Stager DR Jr, Felius J. Visual acuity development after the implantation of unilateral intraocular lenses in infants and young children. JAAPOS. 2005;9(6):527-532. 
26. Drover JR, Stager DR Sr, Morale SE, et al. Improvement in motor development following surgery for infantile esotropia. J AAPOS. 2008;12(2):136-140.

27. Gerth C, Zawadzki RJ, Heon E, Werner JS. High-resolution retinal imaging in young children using a handheld scanner and Fourierdomain optical coherence tomography. J AAPOS. 2009;13(1): $72-74$.
28. Simonsz HJ, Kolling GH, Unnebrink K. Final report of the early vs late infantile strabismus surgery study (ELISSS), a controlled, prospective, multicenter study. Strabismus. 2005;13(4):169-199.

29. Wong AM. Timing of surgery for infantile esotropia: sensory and motor outcomes. Can J Ophthalmol. 2008;43(6):643-651.

30. Do TT. Congenital muscular torticollis: current concepts and review of treatment. Curr Opin Pediatr. 2006;18(1):26-29.

\section{Publish your work in this journal}

Clinical Ophthalmology is an international, peer-reviewed journal covering all subspecialties within ophthalmology. Key topics include: Optometry; Visual science; Pharmacology and drug therapy in eye diseases; Basic Sciences; Primary and Secondary eye care; Patient Safety and Quality of Care Improvements. This journal is indexed on

\section{Dovepress}

PubMed Central and CAS, and is the official journal of The Society of Clinical Ophthalmology (SCO). The manuscript management system is completely online and includes a very quick and fair peer-review system, which is all easy to use. Visit http://www.dovepress.com/ testimonials.php to read real quotes from published authors. 